\title{
Association between vascular comorbidity and glaucoma progression: A four-year observational study
}

\author{
ANA MARIA DASCALU ${ }^{1,2^{*}}$, DANIELA STANA ${ }^{2}$, VANESA ANDRADA NICOLAE ${ }^{1}$, \\ CATALIN CIRSTOVEANU ${ }^{1}$, GETA VANCEA ${ }^{1}$, DRAGOS SERBAN ${ }^{1 *}$ and BOGDAN SOCEA ${ }^{1 *}$ \\ ${ }^{1}$ Faculty of Medicine, 'Carol Davila' University of Medicine and Pharmacy, 020021 Bucharest; \\ ${ }^{2}$ Department of Ophthalmology, Emergency University Hospital Bucharest, 050098 Bucharest, Romania
}

Received October 23, 2020; Accepted November 24, 2020

DOI: $10.3892 /$ etm.2021.9714

\begin{abstract}
Glaucoma, one of the significant causes of blindness worldwide, is a chronic optic neuropathy, characterized by progressive loss of retinal ganglion cells and specific perimetric defects. This study aimed to assess the association between the risk of glaucoma progression and different systemic vascular abnormalities. A 4-year prospective study was carried out on 204 patients diagnosed with open-angle glaucoma. Associated systemic vascular pathology was documented in 102 cases. Progression was encountered in 57 (55.9\%) patients with vascular comorbidities and only in $10(9.8 \%)$ patients with no associated vascular diseases (OR 13.81, $\mathrm{P}<0.01$ ). The vascular risk factors associated with glaucoma progression in the study group were diastolic hypotension (OR 5.444, $\mathrm{P}=0.027$ ), ischemic cardiac disease (OR 5.826; $\mathrm{P}<0.01$ ), peripheral vasospasm (OR 3.108, $\mathrm{P}=0.042)$ and arterial hypertension (OR 2.593, $\mathrm{P}=0.05$ ). Diabetes was not significantly correlated with progression in the study group, but only patients without diabetic retinopathy were included. This study highlights that systemic comorbidities associated with endothelial lesions, atherosclerosis and hypoperfusion can lead to damage to the retinal nerve fiber layer and the underlying conjunctive tissue.
\end{abstract}

\section{Introduction}

Glaucoma, one of the major causes of blindness worldwide, is a chronic optic neuropathy, characterized by progressive loss

Correspondence to: Dr Dragos Serban, Faculty of Medicine, 'Carol Davila' University of Medicine and Pharmacy, 37 Dionisie Lupu Street, 020021 Bucharest, Romania

E-mail: dragos.serban@umfcd.ro

${ }^{*}$ Contributed equally

Abbreviations: OBF, ocular blood flow; OPP, ocular perfusion pressure; BP, blood pressure; OCT, optical coherence tomography; IOP, intraocular pressure

Key words: glaucoma, ocular blood flow, arterial hypertension, hypotension, arteriolosclerosis, ischemia of retinal ganglion cells and specific perimetric defects $(1,2)$. The main risk factor for the onset and progression of glaucomatous damage is considered high intraocular pressure (IOP), which is also the main target of the therapeutic arsenal of glaucoma $(2,3)$. In clinical practice, a significant proportion of cases experience progression, even when IOP is under control and, in normal-tension glaucoma, optic disc changes and visual field defects appear while IOP is considered normal.

Clinical studies have aimed to identify correlations with other risk factors, such as myopia, age, race, family history, central corneal thickness, and diabetes $(4,5)$. There is strong evidence that systemic vascular abnormalities play an important role in the pathophysiology of glaucoma (6-9). Ocular blood flow (OBF) is a key factor for the health of retinal ganglion cells. According to Ohm's law, it depends on ocular perfusion pressure (OPP) and the vascular resistance ratio; the mechanisms of retinal autoregulation can modify the latter $(9,10)$. Clinical data show that OPP correlates better with the occurrence and progression of glaucomatous lesions compared to blood pressure (BP) or IOP alone $(9,11,12)$.

Retinal autoregulation is the complex physiological process by which constant blood flow is ensured despite significant variations in the OPP. The blood flow of the retina is controlled by complex mechanisms that include myogenic, metabolic and hormonal factors $(6,13-15)$. The high consumption of oxygen in the human retina is crucial for normal functioning of the organ. Vascular dysregulation is a primary step initiating glaucomatous damage via OBF instability, affecting the optic nerve and retina by the enhancement of ischemic injury and promoting the apoptosis of retinal ganglion cells. Primary vascular dysregulation, endothelial dysfunction, astrocyte activation and neuronal dysfunction induce compromised neurovascular coupling (6). This leads to periods of reduced nutrient supply (including oxygen and glucose) during neuronal stimulation. Such periods are more likely to occur when OPP is reduced or fluctuates. Changes in arteriolosclerosis additionally bring a vulnerability factor of the optic nerve to small variations in perfusion eye pressure by compromising auto-regulation (15). On the other hand, vascular dysregulation may increase the vulnerability of the optic nerve to slight variations of IOP, BP or metabolic needs of retinal ganglion cells, because in this case, small variations of OPP may cause a significant decrease in OBF, beyond normal limits, resulting in retinal ganglion cell ischemia $(6,7,15)$. 
The objective of this study was to estimate the association of the risk of progression in glaucomatous patients with vascular dysregulation-related comorbidities as an independent factor despite maintaining normal IOP under antiglaucomatous topical therapy.

\section{Patients and methods}

A 4-year-prospective study was carried out in 204 patients diagnosed with open-angle glaucoma and compensated values of intraocular pressure (IOP) under medical treatment, admitted to the Department of Ophthalmology, Emergency University Hospital Bucharest, Romania, during 2015-2019. The Ethics Committee of The Emergency University Hospital Bucharest approved the study, and signed informed consent of all patients enrolled was obtain, according to the Declaration of Helsinki. Two comparative study groups were designed: Group A (no associated vascular comorbidities) ( $\mathrm{n}=102$ patients) and group B (with associated vascular pathology) ( $\mathrm{n}=102$ patients). The groups were matched in regards to glaucoma stage and sex ratio. The two groups were not age-matched, due to the increased incidence of vascular comorbidities, especially arterial hypertension and ischemic coronary disease with age.

All of the patients underwent complex ophthalmological examination, automated perimetry (Optopol PTS-910), fundus photography and optical coherence tomography (OCT) analysis of the optic nerve and peri-papillary retina (SD-OCT, Zeiss). An extensive anamnesis was carried out at admission to document all cardiovascular comorbidities and other possible risk factors for progression. The two groups were comparatively studied for glaucoma progression. Only one eye, the eye with the most advanced glaucomatous lesions, was included in the study. Based on severity of glaucomatous optic nerve damage and visual field (VF) loss the patients were arranged in 4 groups: Preperimetric, early, moderate and advanced glaucoma (Table I).

Exclusion criteria included: Visual acuity $<0.3$, other retinal or neurologic pathology which could be a possible cause of decreased vision and VF abnormalities, and secondary glaucoma. After the initial enrollment, the patients were evaluated every six months by applanation tonometry, VF, OCT and fundus examination, for 48 months.

Statistical analysis. For analysis of the data and establishing the correlations with significant statistical value, SPSS (version 13.0) (SPSS, Inc.) was used. Mean and standard deviation were calculated for the significant parameters. ANOVA, odds ratio (OR) and $\chi^{2}$ test were used to assess the statistical correlation and a $\mathrm{P}<0.05$ was considered to indicate a statistically significant difference.

\section{Results}

Out of the total of 204 patients, at the time of enrollment in the study, $57(27.9 \%)$ patients represented newly diagnosed cases, and $147(72.1 \%)$ were patients previously diagnosed with primitive open-angle glaucoma. Most were female (139 cases), with a sex ratio F:M of 2.13:1. The distribution by age groups showed a peak around 50-55 years, with a mean age $51 \pm 2.1$ years. In group 'A', with no vascular comorbidities, the mean age was $48 \pm 2.3$ years. In group 'B', with associated vascular pathology, the mean age was $62 \pm 1.8$ years. Age and glaucoma stage distribution of the patients in the study groups are presented in Table II.

All patients in the study group achieved target IOP under medical treatment. In group B, the most frequent associated pathologies were: Arterial hypertension and type 2 diabetes $(34.3 \%)$, followed by ischemic cardiac disease $(22.55 \%)$ (Table III).

Of the total 204 patients, monitored over a 48-month period, 67 had perimetrically and/or imagistic documented progression of the glaucomatous disease, despite normal IOP under topical antiglaucomatous therapy. Progression was encountered in 57 (55.9\%) patients from group B (with vascular comorbidities) and only in 10 (9.8\%) patients from group A (Table IV). The mean age of patients who presented progression was significantly higher than the general average both for group A $(52 \pm 2.7$ vs. $48 \pm 2.3$ years, $\mathrm{P}=0.014)$, and group $\mathrm{B}(62 \pm 1.8$ vs. $66 \pm 8.3$ years, $\mathrm{P}=0.02)$, thus age was positively associated with progression.

The percentages in which different systemic vascular conditions were found in the entire study group and in the group of patients who had functional or structural confirmed glaucoma progression were studied comparatively (Table V).

Statistical analysis found that cardio-vascular ischemic diseases, diastolic hypotension, peripheral vasospasm and chronic arterial hypertension were strongly associated with glaucoma progression (OR: 5.826, 5.444, 3.108 and 2.593 respectively) (Table V). In the present study, 7 patients out of a total of $204(3.43 \%)$ presented low diastolic blood pressure (below $65 \mathrm{mmHg}$ ), either permanent or with documented nocturnal dips (by 24-h Holter monitoring). Progression was documented in 5 of these cases.

Diabetes was not a significant risk factor for glaucoma progression in the present study. This associated pathology was common both in the population without progression and in the group in which the disease progressed (OR: 0.874 vs. OR: 1.467). One explanation would be that patients with diabetic retinopathy were not included in the study, in order not to influence the assessment of the perimetric progression of glaucomatous disease. Therefore, being present only in patients with diabetes, but without retinopathy, we can consider that the vascular impairment related to diabetes is insignificant for the retinal autoregulation in these cases.

\section{Discussion}

Ocular blood flow (OBF) is a key factor for the health of retinal ganglion cells. According to Ohm's law, it depends on ocular perfusion pressure (OPP) and vascular resistance ratio; the mechanisms of retinal autoregulation can modify the latter (10). OPP represents the arterial-venous pressure driving blood through the retinal vasculature. Although direct measurement of OPP can be performed experimentally, it is a complicated procedure. In practice, it can be approximated that the mean arterial pressure in the ophthalmic artery is equal to $2 / 3$ of the pressure measured at the level of the brachial artery and that retinal venous pressure is similar to IOP. However, venous flow is known to occur in the retinal circulation (16). The venous pressure must slightly exceed IOP $(13,14)$. OPP is the result of the balance that is established between blood pressure (BP) and IOP. 
Table I. Staging of glaucoma in the study groups.

\begin{tabular}{|c|c|c|c|c|}
\hline & Preperimetric glaucoma & Early glaucoma & Moderate glaucoma & Advanced glaucoma \\
\hline IOP at diagnosis & $>21 \mathrm{mmHg}$ & $>21 \mathrm{mmHg}$ & $>21 \mathrm{mmHg}$ & $>21 \mathrm{mmHg}$ \\
\hline $\begin{array}{l}\text { VF changes } \\
\text { (automated } \\
\text { perimetry) }\end{array}$ & Normal aspect & $\begin{array}{l}\text { Non-specific changes } \\
\text { (enlargement of blind } \\
\text { spot, nasal field narrowing) }\end{array}$ & $\begin{array}{l}\text { Various typical } \\
\text { glaucomatous } \\
\text { scotomas }\end{array}$ & $\begin{array}{l}\text { Advanced VF defects: } \\
\text { nasal step, confluent } \\
\text { arcuate scotomas, ring } \\
\text { scotomas, within } 10^{\square} \\
\text { of central vision }\end{array}$ \\
\hline $\begin{array}{l}\text { Optic disk and RNFL } \\
\text { changes (OCT and } \\
\text { fundus examination) }\end{array}$ & $\begin{array}{l}\text { Suggestive for } \\
\text { glaucoma: Enlargement } \\
\text { of C/D ratio (0.3-0.5), } \\
\text { focal loss, thinning } \\
\text { of RNFL }\end{array}$ & $\begin{array}{l}\text { Suggestive for glaucoma: } \\
\text { Enlargement of C/D ratio } \\
(0.3-0.5), \text { focal loss, thinning } \\
\text { of RNFL }\end{array}$ & $\begin{array}{l}\text { Optic disk changes } \\
\text { (increased cupping } \\
0.5-0.7 \text {, focal } \\
\text { loss/thinning of the } \\
\text { RNFL +/-neuroretinal } \\
\text { rim) }\end{array}$ & $\begin{array}{l}\text { Optic disk changes } \\
\text { (optic disc cupping } \\
>0.7 \text {, focal or diffuse } \\
\text { lesions of the optic } \\
\text { disk and nerve fibers } \\
\text { layer) }\end{array}$ \\
\hline
\end{tabular}

IOP, intraocular pressure; VF, visual field; RNFL, retinal nerve fiber layer; OCT, optical coherence tomography.

Table II. Age distribution and clinical stages of glaucoma at admission of the cases.

\begin{tabular}{|c|c|c|c|c|c|}
\hline Age & No. & Preperimetric & Incipient & Moderate & Advanced \\
\hline 35-39 years & 24 & 5 & 9 & 7 & 3 \\
\hline 40-44 years & 12 & 0 & 6 & 6 & 0 \\
\hline $45-49$ years & 18 & 4 & 6 & 5 & 3 \\
\hline $50-54$ years & 34 & 8 & 8 & 9 & 9 \\
\hline $55-59$ years & 29 & 11 & 8 & 8 & 2 \\
\hline 60-64 years & 30 & 6 & 11 & 7 & 6 \\
\hline $65-69$ years & 17 & 3 & 7 & 4 & 3 \\
\hline $70-75$ years & 25 & 3 & 13 & 5 & 4 \\
\hline$>75$ years & 15 & 2 & 7 & 4 & 2 \\
\hline Total & 204 & 42 & 75 & 55 & 32 \\
\hline
\end{tabular}

Table III. Vascular abnormalities in group B.

\begin{tabular}{lc}
\hline Vascular abnormality & No. of cases \\
\hline Arterial hypertension & 35 \\
Ischemic cardiac disease & 23 \\
Diastolic hypotension $(<65 \mathrm{mmHg})$ & 7 \\
Peripheric vasospasm & 2 \\
Diabetes type 2 & 35 \\
Total & 102 \\
\hline
\end{tabular}

A constant OBF can be maintained in normal subjects up to an increase of IOP at values of $27-30 \mathrm{mmHg}$, which would mean a decrease in the perfusion eye pressure of $40-50 \%$ at the average $\mathrm{BP}$ of $100 \mathrm{mmHg}$; but also, in the case associated with an increase of OPP up to 20-60\%, as happens during isometric physical exercise $(7,15)$. In experimental studies, increased IOP induces retinal vasodilation to increase compensatory
OBF $(7,15,17)$. This is achieved by modifying the vascular caliber via $\mathrm{Ca}^{++}$blocking channels, which generate vasodilation. The mediators of these mechanisms include oxygen, carbon dioxide, angiotensin-II, adenosine, nitric oxide (NO), and endothelin-1 (14,18). Metabolic factors, such as variations in the partial pressures of $\mathrm{O}_{2}$ and $\mathrm{CO}_{2}$, are triggers for endothelin-1-mediated vasoconstriction and respectively vasodilation-mediated by NO (19). Retinal ganglion cells and their axons, endothelium and glial cells, such as astrocytes, form a 'neurovascular unit', which contributes to the homeostasis of the microenvironment and OBF in optic nerve head $(\mathrm{ONH})$ and retina, via vascular autoregulation, glial support, the balance between ET-1 and NO, trophic supply, proper blood-brain barrier (BBB) and controlled immunity (20). In the central nervous system, astrocytes have a well-known neuroprotective effect, through multiple mechanisms: Angiogenetic, immunomodulatory, neurogenic, antioxidant and modulating synaptic transmission (21). In a normal state, astrocytes support the axons they ensheathe, but in response to injury/disease, they remodel and become reactive, inducing changes in gene expression, morphology and function (22). There is a standing 
Table IV. Incidence of glaucoma progression in study groups A and B; correlations with age and systemic vascular abnormalities.

\begin{tabular}{|c|c|c|c|c|c|}
\hline Age & Group A & Group A progression & Group B & Group B progression & Progression (total) \\
\hline 35-39 years & 21 & 1 & 3 & 2 & 2 \\
\hline 40-44 years & 10 & 1 & 2 & 4 & 5 \\
\hline $45-49$ years & 16 & 2 & 2 & 3 & 5 \\
\hline $50-54$ years & 23 & 3 & 11 & 8 & 11 \\
\hline $55-59$ years & 14 & 2 & 15 & 6 & 8 \\
\hline $60-64$ years & 9 & 1 & 21 & 10 & 11 \\
\hline $65-69$ years & 2 & 0 & 15 & 7 & 7 \\
\hline $70-75$ years & 4 & 1 & 21 & 9 & 10 \\
\hline$>75$ years & 1 & 0 & 14 & 8 & 8 \\
\hline Mean age (years) & $48 \pm 2.3$ & $52 \pm 2.7$ & $62 \pm 1.8$ & $66 \pm 8.3$ & $60 \pm 12.6$ \\
\hline Total & 102 & 10 & 102 & 57 & 67 \\
\hline
\end{tabular}

Table V. Distribution of the vascular comorbidities in the total group and the group of patients with glaucomatous progression.

\begin{tabular}{|c|c|c|c|c|}
\hline Vascular comorbidity & Total study group n (\%) & Glaucoma progression $\mathrm{n}(\%)$ & OR & P-value ( $\chi^{2}$ test $)$ \\
\hline Arterial hypertension & $35(17.15)$ & $18(26.86)$ & 2.593 & 0.050 \\
\hline Ischemic cardiac disease & $23(11.27)$ & $16(23.88)$ & 5.826 & $<0.010$ \\
\hline Type 2 diabetes & $35(17.15)$ & $14(20.89)$ & 1.467 & 0.322 \\
\hline Peripheral vasospasm & $2(0.98)$ & $2(2.98)$ & 3.108 & 0.042 \\
\hline Diastolic hypotension $(<65 \mathrm{mmHg})$ & $7(3.4)$ & $5(7.64)$ & 5.444 & 0.027 \\
\hline Total & $204(50)$ & $57(85.07)$ & 13.8172 & $<0.010$ \\
\hline
\end{tabular}

OR, odds ratio.

question in glaucoma research, whether reactive astrocytes in the lamina region are harmful or beneficial for visual outcome. As in the brain, blood flow in the retina is also controlled by neurovascular coupling $(15,22)$. This means that the retina increases its blood flow to regions in which neurons are activated, via prostaglandin-mediated vasodilatation. This is carried out to provide more oxygen and glucose to the active neurons. In recent years, evidence suggests that astrocytes play a crucial role in mediating this vasodilator signal $(22,23)$.

Arterial hypertension and glaucoma. In the present study, we found that chronic arterial hypertension was highly correlated with glaucoma progression (OR 2.593, $\mathrm{P}=0.05)$. In the literature, the interrelations of high BP and glaucoma are more complex. Klein et al, in the Beaver Dam Eye Study (24), found an increase in IOP of $0.24 \mathrm{mmHg}$ for every $10 \mathrm{mmHg}$ of systolic BP. The pathophysiological mechanisms include an increase in the ultrafiltration of the aqueous humor, an increase in the pressure in the episcleral veins, with secondary reduced trabecular filtration, but also an increase in the general sympathetic tonus with age. Experimental studies on animal models confirmed the hypothesis that the OBF is the primary determinant of retinal ganglion cell integrity $(7,25)$. Low BP exacerbates IOP-induced ischemia, while increased BP, at least in the short term, provides some protection. In these models, $\mathrm{BP}$ and IOP are experimentally increased and decreased for only a short time, up to $10 \mathrm{~min}$, so the long-term consequences of arterial hypertension at the level of the retinal ganglion cells cannot be evaluated (7).

Therefore, the findings cannot be extrapolated to adults with chronic arterial hypertension, as they do not take into account vascular changes in arteriolosclerosis and endothelial dysfunction. Clinical trials, across large population groups, have different results regarding the effect of high BP on glaucomatous progression. Some extensive clinical studies show, paradoxically, that chronic arterial hypertension may increase the risk of glaucoma, despite the protection that should be associated with increased OPP $(24,26)$. In contrast, others revealed a protective role of increased $\mathrm{BP}(8,10,19,26-32)$. The Baltimore Eye Survey (31) showed a relationship dependent on the age of the subjects: Protective effect for the young and a risk factor for the elderly, probably explained by the associated peripheral vascular changes. In clinical practice, in older individuals, glaucoma and arterial hypertension, treated or not coexist frequently. Clinical studies support the existence of a clinical paradox: Too aggressive lowering of BP is not beneficial for tissue perfusion, not only at the level of the retina and optic nerve but also in the brain and heart $(4,24)$.

Diastolic hypotension (dips). Low diastolic BP (DBP) has the immediate effect of reducing OPP, with insufficient ocular perfusion. Numerous studies, across large population groups, 
show a high correlation between low OPP and prevalence, incidence and progression of glaucoma. The Egna-Neumarkt Study (8) demonstrated that low diastolic pressure below $50 \mathrm{mmHg}$ is associated with a 4.5 -fold prevalence of glaucoma compared to those with a diastolic pressure above $65 \mathrm{mmHg}$. In the Proyector VER study (32), patients with diastolic pressure below $45 \mathrm{mmHg}$ were found to have a 3 -fold risk of developing glaucoma in comparison to subjects with DBP above $65 \mathrm{mmHg}$. The Barbados Eye Study (33) demonstrated a 2-fold risk of glaucoma in individuals with arterial hypotension. Nocturnal -dips- of more than $10 \mathrm{mmHg}$ compared to DBP baseline were found to be another documented risk factor for glaucoma progression. These observations correlate clinically with nocturnal IOP increases, related to the decubitus position, which have a negative synergistic effect, reducing OPP. Furthermore, the risk of glaucoma progression depends on the duration and the amplitude of those dips $(33,34)$.

Therefore, therapeutic planning of glaucomatous patients should also include 24-h automated monitoring of BP, especially in those cases with IOP within the limits of the target values, but showing progression of VF defects. Moreover, clinical studies show that patients with low OPP or large nocturnal 'dips' in BP frequently present with autoregulation disorders both in the retinal vasculature and in the peripheral circulation in general, the Flammer phenomenon $(15,19,35)$.

The therapeutic strategy of glaucomatous patients with low BP should include, in addition to ocular hypotensive therapy, hygiene-dietary measures intended to increase BP to the limit of average values: Easy isometric (aerobic) exercise, loaded with night salt and proper hydration. In patients with treated arterial hypertension, the adjustment of antihypertensive therapy to less aggressive target is indicated (36).

Peripheral vasospasm. The association of glaucoma with peripheral vasospasm was found to be a significant risk factor for progression $\left(\mathrm{P}=0.042\right.$ for $\chi^{2}$ test). The relative risk for the 'progression' cohort had a significant supraunitarian value: 3.108. Clinical studies support evidence that there is an increased incidence of peripheric autoregulation disorders in patients with glaucoma $(8,28-32,36,37)$. This phenomenon, described by Flammer for the first time as "primitive vascular dysregulation' refers to abnormal changes in the microcirculation under mechanical or mental stress or in response to temperature variations, in apparently healthy subjects. These dysfunctions may involve both vasoconstrictions-vasodilatation response, mediated by endothelin and NO, respectively, as key factors of retinal autoregulation during isometric exercises, but also astrocyte-mediated vasodilation, the so-called 'neurovascular coupling' $(11,35)$. Retinal blood flow is mostly regulated by the endothelial cell-derived substances that are collectively known as endothelium-derived vasoactive compounds, acting both abluminal and intraluminally. Patients with primary vascular dysregulation often have a high level of endothelin-1. Trivli et al highlight endothelin1-related modified vasoreactivity in normotensive glaucoma patients, which has also elevated plasma levels of endothelin-1 in cold stimulation, so widespread vasoconstriction and peripheral blood flow insufficiency (19).

Cardio-vascular ischemic diseases. Cardio-vascular ischemic diseases represent a significant risk factor for glaucoma progression $(\mathrm{P}<0.01$, OR: 5.826), which could be explained by the disruption of the autoregulation mechanism and decreased blood flow to the optic nerve. Some clinical studies also revealed a higher proportion of ischemic heart disease development among open-angle glaucoma patients. This may be explained to the similar underlying mechanisms of both diseases. The presence of glaucoma in patients with heart failure may be related to low cerebral blood flow and may be a poor prognostic factor for heart disease (36-41).

Diabetes. The correlations between diabetes and glaucoma are controversial. Some studies have found diabetes to be a risk factor in glaucoma (42-46), and others find no correlation or even a negative correlation (47). In the present study, we found no correlation between these two frequent encountered pathologies, but only diabetic patients without diabetic retinopathy were included. Diabetic microcirculation impairment leads to retinal fiber layer damage by multiple pathological pathways: Oxidative stress, increased levels of retinal inflammation biomarkers and disruption of vasculo-retinal barrier $(42,43,46)$.

Vascular abnormalities consequently interfere in multiple ways in the pathophysiology of glaucoma. Arterial hypotension induces ischemia and hypoxic stress in the retinal ganglion cells. The nocturnal increase in IOP related to the decubitus position, associated with nocturnal dips in diastolic $\mathrm{BP}$, may lead to a significant decrease in ocular perfusion pressure, thus explaining the strong correlation with glaucomatous progression. Local disorders associated with primary or secondary auto-regulation may have a similar effect. Age is another factor positively associated with progression, both by an increased incidence of systemic vascular diseases and by physiological decreased retinal autoregulation. One limitation of the present study was that the two groups were not age-matched, given the difficulty in identifying older patients without vascular abnormalities and on the other hand, the low incidence of vascular-associated pathology in younger patients below 50 years of age. On the other hand, age and vascular pathologies are well correlated; the prevalence of arteriolosclerosis, endothelial dysfunction and dysregulation being higher in older people.

This study demonstrated that systemic comorbidities associated with endothelial dysfunction, lesions and atherosclerosis can lead to damage to the retinal nerve fiber layer and the underlying connective tissue. Arterial hypertension, ischemic cardiac disease, peripheral vasospasm and arterial hypotension are hemodynamic risk factors, significantly associated with glaucoma progression, despite maintaining IOP within normal limits, by impaired ocular blood flow. In glaucomatous patients, with documented progression, despite low IOP values under treatment, a careful evaluation of the associated hemodynamic risk factors, including 24-h monitoring of BP can be useful in therapeutic planning.

\section{Acknowledgements}

Not applicable.

\section{Funding}

No funding was received. 


\section{Availability of data and materials}

All data generated or analyzed during this study are included in this published article.

\section{Authors' contributions}

AMD achieved the conception and design of this study. AMD, VAN and DS were responsible for the data collection and analysis. DAM, GV, BS, CC and DS were in charge of the literature review and drafting the manuscript. DS revised critical perspective for important intellectual content. The final version was read and approved by all the authors.

\section{Ethics approval and consent to participate}

The study was conducted according to the World Medical Association Declaration of Helsinki, using a protocol approved by the local Bioethics Committee from the University Emergency Clinical Hospital (Bucharest, Romania). All patients previously signed an informed written consent concerning the hospitalization and investigation.

\section{Patient consent for publication}

Not applicable.

\section{Competing interests}

The authors declare that they have no competing interests.

\section{Authors' information}

Ana Maria Dascalu: https://orcid.org/0000-0002-7474-2395.

\section{References}

1. Mahabadi N, Foris LA and Tripathy K: Open Angle Glaucoma. [Updated 2020 Nov 20]. In: StatPearls [Internet]. Treasure Island (FL), StatPearls Publishing, 2020. Available from: https://www. ncbi.nlm.nih.gov/books/NBK441887/.

2. Weinreb RN, Leung CK, Crowston JG, Medeiros FA, Friedman DS, Wiggs JL and Martin KR: Primary open-angle glaucoma. Nat Rev Dis Primers 2: 16067, 2016.

3. Weinreb RN, Aung T and Medeiros FA: The pathophysiology and treatment of glaucoma: A review. JAMA 311: 1901-1911, 2014.

4. Zhou M, Wang W, Huang W and Zhang X: Diabetes mellitus as a risk factor for open-angle glaucoma: A systematic review and meta-analysis. PLoS One 9: e102972, 2014.

5. Salowe R, Salinas J, Farbman NH, Mohammed A, Warren JZ, Rhodes A, Brucker A, Regina M, Miller-Ellis E, Sankar PS, et al: Primary open-angle glaucoma in individuals of african descent: A review of risk factors. J Clin Exp Ophthalmol 6: 450, 2015

6. Cherecheanu AP, Garhofer G, Schmidl D, Werkmeister R and Schmetterer L: Ocular perfusion pressure and ocular blood flow in glaucoma. Curr Opin Pharmacol 13: 36-42, 2013.

7. He Z, Vingrys AJ, Armitage JA and Bui BV: The role of blood pressure in glaucoma. Clin Exp Optom 94: 133-149, 2011.

8. Bonomi L, Marchini G, Marraffa M, Bernardi P, Morbio R and Varotto A: Vascular risk factors for primary open angle glaucoma: The Egna-Neumarkt study. Ophthalmology 107: 1287-1293, 2000.

9. Cantoe E, Méndez F, Rivera C, Castillo A and MartínezBlanco A: Blood pressure, ocular perfusion pressure and open-angle glaucoma in patients with systemic hypertension. Clin Ophthalmol 12: 1511-1517, 2018.
10. Luo X, Shen YM, Jiang MN, Lou XF and Shen Y: Ocular blood flow autoregulation mechanisms and methods. J Ophthalmol 2015: 864871, 2015.

11. Gore V, Shah P, Kanhere M and Gore S: Relationship between optical perfusion pressure and systemic blood pressure on glaucoma: Case-control study. Oman J Ophthalmol 12: 150-155, 2019.

12. Fuchsjäger-Mayrl G, Wally B, Georgopoulos M, Rainer G, Kircher K, Buehl W, Amoako-Mensah T, Eichler HG, Vass C and Schmetterer L: Ocular blood flow and systemic blood pressure in patients with primary open-angle glaucoma and ocular hypertension. Invest Ophthalmol Vis Sci 45: 834-839, 2004.

13. Stodmeister R: The pulsation and the pressure of the central retinal vein and their relation to glaucoma damage and therapy. Klin Monbl Augenheillkd 225: 632-636, 2008 (In German).

14. Morgan WH, Hazelton ML, Balaratnasingamm C, Chan H, House PH, Barry CJ, Cring SJ and Yu DY: The association between retinal vein ophthalmodynamometric force change and optic disc excavation. Br J Ophthalmol 93: 594-596, 2009.

15. Schmidl D, Garhofer G and Schmetterer L: The complex interaction between ocular perfusion pressure and ocular blood flow-relevance for glaucoma. Exp Eye Res 93: 141-155, 2011.

16. Van Keer K, Breda JB, Pinto LA, Stalmans I and Vandewalle E: Estimating mean ocular perfusion pressure using mean arterial pressure and intraocular pressure. Invest Ophthalmol Vis Sci 57: 2260, 2016

17. Gericke A, Mann C, Zadeh JK, Musayeva A, Wolff I, Wang M, Pfeiffer N, Daiber A, Li H, Xia N and Prokosch V: Elevated intraocular pressure causes abnormal reactivity of mouse retinal arterioles. Oxid Med Cell Longev 2019: 9736047, 2019.

18. Guidoboni G, Harris A and Sacco R (eds): Ocular fluid dynamics: In: Anatomy, Physiology, Imaging Techniques, and Mathematical Modeling. Springer Nature, Switzerland, pp6167-6208, 2019.

19. Trivli A, Koliarakis I, Terzidou C, Goulielmos GN, Siganos CS, Spandidos DA, Dalianis G and Detorakis ET: Normal-tension glaucoma: Pathogenesis and genetics. Exp Ther Med 17: 563-574, 2019.

20. Wareham LK and Calkins DJ: The neurovascular unit in glaucomatous neurodegeneration. Front Cell Dev Biol 8: 452, 2020.

21. Sun D, Moore S and Jakobs TC: Optic nerve astrocyte reactivity protects function in experimental glaucoma and other nerve injuries. J Exp Med 214: 1411-1430, 2017.

22. Mursch-Edlmayr AS, Pick1 L, Calzetti G, Waser K, Wendelstein J, Beka S, Aranha dos Santos V, Luft N, Schmetterer L and Bolz N: Comparison of neurovascular coupling between normal tension glaucoma patients and healthy individuals with laser speckle flowgraphy. Curr Eye Res 45: 1438-1442, 2020.

23. Filosa JA, Morrison HW, Iddings JA, Du W and Kim KJ: Beyond neurovascular coupling, role of astrocytes in the regulation of vascular tone. Neuroscience 323: 96-109, 2016.

24. Klein BE, Klein R and Knudtson MD: Intraocular pressure and systemic blood pressure: Longitudinal perspective: The beaver dam eye study. Br J Ophthalmol 89: 284-287, 2005.

25. van Koeverden AK, He Z, Nguyen CTO, Vingrys AJ and Bui BV: Systemic hypertension is not protective against chronic intraocular pressure elevation in a rodent model. Sci Rep 8: 7107, 2018.

26. Costa VP, Arcieri ES and Harris A: Blood pressure and glaucoma. Br J Ophthalmol 93: 1276-1282, 2009.

27. Memarzadeh F, Ying-Lai M, Chung J, Azen SP and Varma R; Los Angeles Latino Eye Study Group: Blood pressure, perfusion pressure, and open-angle glaucoma: The los angeles latino eye study. Invest Ophthalmol Vis Sci 51: 2872-2877, 2010.

28. Bowe A, Grünig M, Schubert J, Demir M, Hoffmann V, Kütting F, Pelc A and Steffen HM: Circadian variation in arterial blood pressure and glaucomatous optic neuropathy-a systematic review and meta-analysis. Am J Hypertens 28: 1077-1082, 2015.

29. Topouzis F, Coleman AL, Harris A, Jonescu-Cuypers C, Yu F, Mavroudis L, Anastasopoulos E, Pappas T, Koskosas A and Wilson RM: Association of blood pressure status with the optic disk structure in non-glaucoma subjects: The thessaloniki eye study. Am J Ophthalmol 142: 60-67, 2006.

30. Hulsman CA, Vingerling JR, Hofman A, Witteman JC and de Jong PT: Blood pressure, arterial stiffness, and open-angle glaucoma: The rotterdam study. Arch Ophthalmol 125: 805-812, 2007.

31. Tielsch JM, Katz J, Quigley HA, Javitt JC and Sommer A: Diabetes, intraocular pressure, and primary open-angle glaucoma in the baltimore eye survey. Ophthalmology 102: 48-53, 1995. 
32. Quigley HA, West SK, Rodriguez J, Munoz B, Klein R and Snyder R: The prevalence of glaucoma in a population-based study of Hispanic subjects: Proyecto VER. Arch Ophthalmol 119: $1819-1826,2001$.

33. Leske MC, Wu SY, Hennis A, Honkanen R and Nemesure B; BESs Study Group: Risk factors for incident open-angle glaucoma: The barbados eye studies. Ophthalmology 115: 85-93, 2008.

34. Melgarejo JD, Lee JH, Petitto M, Yépez JB, Murati FA, Jin Z, Chávez CA, Pirela RV, Calmón GE, Lee W, et al: Glaucomatous optic neuropathy associated with nocturnal dip in blood pressure: Findings from the maracaibo aging study. Ophthalmology 125: 807-814, 2018

35. Hainarosie IM, Pietrosanu C, Zainea V, et al: Orbital decompression in basedow disease. Conference: National conference on otorhinolaryngology and cervical and facial surgery/national ENT, head and neck surgery conference location: Arad, Romania date: Jun 06-09, 2018. Sponsor(S): Univ vest vasile goldis proceedings of national Ent, Head And Neck Surgery Conference, pp241-246, 2018.

36. Okumura Y, Yuki K and Tsubota K: Low diastolic blood pressure is associated with the progression of normal-tension glaucoma Ophthalmologica 228: 36-41, 2012.

37. Flammer $\mathbf{J}$ and Konieczka K: The discovery of the Flammer syndrome: A historical and personal perspe. EPMA J 8: 75-97, 2017.

38. Diaconu C, Paraschiv B and Stanescu AM: Arterial hypertension, a frequent comorbidity in diabetes: The perioperative management. Conference: 35 th Balkan medical week on healthy ageing-an endless challenge location: Athens, Greece date: Sep 25-27, 2018 Proceedings of the 35th Balkan Medical Week, pp15-20, 2018.

39. Pantea-Stoian A, Ditu G, Stefan DS, et al: Diabetic retinopathy is a possible prognostic factor for chronic kidney disease progression? Conference: 2 nd International conference on interdisciplinary management of diabetes mellitus and its complications, INTERDIAB 2016 location: Bucharest, Romania date: Mar 03-05, 2016. Sponsor(S): Assoc renal metabol \& nutrit studies; Romanian Soc Diabet Nutr \& Metabol Dis; Astrazeneca diabet; novo nordisk; sanofi. Interdiab 2016: Diabetes mellitus as cardiovascular disease book series: International conference on interdisciplinary management of diabetes mellitus and its complications, p339, 2016.
40. Meira-Freitas D, Melo LA Jr, Almeida-Freitas DB and Paranhos A: Glaucomatous optic nerve head alterations in patients with chronic heart failure. Clin Ophthalmol 6: 623-629, 2012.

41. Stanciu AE, Stanciu MM and Vatasescu RG: NT-proBNP and CA 125 levels are associated with increased pro-inflammatory cytokines in coronary sinus serum of patients with chronic heart failure. Cytokine 111: 13-19, 2018

42. Chen YY, Hu HY, Chu D, Chen HH, Chang CK and Chou P: Patients with primary open-angle glaucoma may develop ischemic heart disease more often than those without glaucoma: An 11-year population-based cohort study. PLoS One 11: e0163210, 2016.

43. Zhao YX and Chen XW: Diabetes and risk of glaucoma: Systematic review and a meta-analysis of prospective cohort studies. Int J Ophthalmol 10: 1430-1435, 2017.

44. Ardeleanu V, Toma A, Pafili K, Papanas N, Motofei I, Diaconu CC, Rizzo M and Stoian AP: Current pharmacological treatment of painful diabetic neuropathy: A narrative review. Medicina (Kaunas) 56: 25, 2020.

45. Mazilu L, Stănculeanu DL, Gheorghe AD, Voinea F, Suceveanu AP, Pițuru S, Diaconu CC, Parepa IR, Stoian AP, Pop CS and Suceveanu AI: Incidence of chemotherapy-induced peripheral neuropathy in cancer patients in clinical practice. Farmacia 67: 472-476, 2019.

46. Stoian AP, Mitrofan G, Colceag F, Suceveanu AI, Hainarosi R, Pituru S, Diaconu CC, Timofte D, Nitipir C, Poiana C and Serafinceanu C: Oxidative stress in diabetes a model of complex thinking applied in medicine. Rev Chim (Bucharest) 69: 2515$2519,2018$.

47. Ozcura F and Aydin S: Is diabetes mellitus a risk factor or a protector for primary open angle glaucoma? Med Hypotheses 69: 233-234, 2007. 